\title{
Exploring the Effectiveness of Deliberate Computer-Assisted Language Learning
}

\author{
Andrew Obermeier \\ Kyoto University of Education
}

\begin{abstract}
This article presents a work-in-progress focused on developing an experiment to investigate the effectiveness of different types of deliberate paired-associate computer-assisted language learning (CALL). First, the rationale for Japanese EFL learners' current need for doubling their efforts with this technique is explained. Next, an overview of research regarding the interface in second language acquisition is presented. This is followed by an explanation of results from a recent experiment. Questions and issues raised in that experiment are then discussed with regard to a proposal for a subsequent experiment that will be conducted during the semester starting in April 2020. In this proposed study, different conditions within Internet-based flashcard study will be the major experimental learning component. Psycholinguistic response time measures will be the main dependent variable, aimed at gauging gains in nondeclarative, or tacit L2 knowledge. In addition, online declarative measures and traditional offline measures of declarative knowledge will be used.
\end{abstract}

\section{Background}

For English learners in Japan, vocabulary size and vocabulary knowledge quality are two areas with deficiencies that must be addressed by institutions, researchers, teachers, and learners. Research concerned with vocabulary size emphasizes the knowledge gap of most L2 learners and the need for them to learn and remember large numbers of words. In Schmitt's (2008) review of instructed second language vocabulary acquisition, he asserts that English as a Foreign Language (EFL) learners are faced with a daunting learning task if they truly wish to achieve adequate proficiency; in order to read common native speaker-level texts, 8,000 to 9,000 word families must be known, and for oral discourse estimates range from 5,000 to 7,000 word families. Considering these benchmarks, it can be seen that Japanese university graduates know far fewer words than the number that they need to know to function in English in meaningful, unhindered ways. In a cross-sectional design in which 3,449 Japanese university students took the Vocabulary Size Test (Nation \& Beglar, 2007), McLean, Hogg, and Kramer (2014) estimated that the average university learner of English has a receptive vocabulary size of only 3,715 word families. To address the issue of deficient vocabulary size, Japanese schools ranging from elementary to university must continue to implement great increases in vocabulary size goals specified in curricula, and specify methods to help students learn the words. 
Another important issue for teachers and researchers to address is with regard to the quality ${ }^{1}$ of vocabulary knowledge that is being developed and measured. In Japan, the overwhelming amount of test-focused English language learning required to pass entrance examinations has been well documented (Berwick \& Ross, 1989; Gorsuch, 1995; Miyazaki, 1981). Such a situation has resulted in highly unbalanced high school curriculums, with a disproportional emphasis on deliberately teaching declarative knowledge that will be useful when taking tests. Schmitt (2008) stresses the need for principled and balanced learning, teaching, and material development. Vocabulary learning programs need to include both intentional and incidental learning opportunities. An example curriculum that balances intentional and incidental learning activities in a university-wide EFL reading program is explained by Hunt and Beglar (2005). For teachers and program designers to integrate intentional and incidental vocabulary learning, the four strands of meaning-focused input, meaning-focused output, language-focused learning, and fluency development, suggested by Nation, provide a useful structure (Nation, 2007; Nation \& Yamamoto, 2012). In this way, previous studies concur that the average Japanese EFL learner needs to learn more than twice as many words as they currently learn by the time they graduate from university, and they need to learn these words in a way that balances intentional and incidental learning methods. That is to say, they need to learn many more words and develop higher quality knowledge of them.

This article is organized as follows: first, previous research on the interface in second language acquisition is reviewed. Next, in an experiment that operationalizes interface constructs in terms of online processing measures, the effects of flashcard-based learning will be discussed from a recently completed study by the author (under review). In this study, the popular Internet-based software Quizlet was used extensively for the deliberate paired-associate learning condition. Results focused mainly on measuring response times to investigate nondeclarative knowledge development and online processing abilities, and a more traditional declarative knowledge measure was also used. The final part of the article will discuss the next step that will be taken to build on findings from this recent research. The next experiment will similarly focus on deliberate learning activities and response time experiments to measure effects of this learning in terms of declarative, automatized declarative, and nondeclarative knowledge gains.

\section{Deliberate Paired Associate Flashcard Learning and the Interface}

The above rationale for the necessity to balance between intentional and incidental learning is rooted in the central theme of second language acquisition research on the interface. The overriding takeaway from this research is this need for balance between implicit and explicit learning and knowledge types. However, the greater effectiveness of explicit learning demonstrated in a multitude of studies confirms that deliberate learning should be positioned in the lead to drive acquisition (e.g., Doughty \& Williams, 1998; Ellis, 2005; Hulstijn, 2003; Norris \& Ortega, 2000). To close the problematic vocabulary size gap mentioned in the previous section, learners need to know that they can intentionally move forward on a clear path, 
and systematically learn large numbers of words. Flashcard learning is an essential strategy that enables learners to do this and should be included within any well-balanced language learning program (Nation, 2007, 2013; Nation \& Webb, 2011; Nation \& Yamamoto, 2012). Thanks to modern technology, in addition to paper-based flashcards, learners can add digital flashcard learning to their language learning strategy repertoire to greatly increase the variety, convenience, systematization, excitement, enjoyability, and functionality of their practice. Digital flashcard learning is a strategy that has a vast potential to empower effective learning at all ages and levels, and there are abundant online applications available. Nakata (2011) conducted a thorough evaluation of nine popular, free, and available flashcard-based applications, offering valuable insights regarding which applications are best for different learning and teaching purposes. It is an essential strategy that is widely available on the Internet and must be incorporated into any serious L2 learner's toolbox. ${ }^{2}$

Interface research has been central to the study of second language acquisition research for over 30 years. The first phase of the discussion was framed with regard to the relationship between explicit and implicit learning and knowledge, when Krashen (1982) famously began the discussion by controversially asserting his extreme position distinguishing between explicit learning and implicit knowledge acquisition. His no interface hypothesis stated that explicitly learned language can never be acquired as implicit knowledge. DeKeyser (1997, 1998) countered this position with the strong interface hypothesis, proposing that when explicit knowledge is practiced to the point of becoming automatized, it interfaces strongly with implicit knowledge development. This first stage of interface research culminated in the 2005 thematic issue of Studies in Second Language Acquisition. This seminal issue began with a brief introduction in which Hulstijn (2005) outlined much needed definitional distinctions between the constructs of implicit and explicit learning, implicit and explicit knowledge, and implicit and explicit memory. The issue consisted of five experiments concerned with the interface and was highlighted by a psychometric study by Ellis (2005b) that focused on measuring interface constructs. This issue culminated with a broad review by Ellis (2005a) that drew widely from the fields of applied linguistics, psycholinguistics, neurology, and cognitive science. His review took the middle ground between the no interface and strong interface positions, arguing that they are both partially correct. He argued that although implicit and explicit knowledge are completely separate neurological entities, based in distinct parts of the brain, they nevertheless interact dynamically in implicit and explicit learning processes to foster second language acquisition. Of these three positions, the no interface hypothesis has been for the most part rejected, and most researchers see the interface as ranging somewhere between the strong and the weak.

In 2015, a second special issue of Studies in Second Language Acquisition revisited the interface theme, and in the introduction, Andringa and Rebuschat (2015) focused on three central issues: the role of awareness; methodological concerns for processes of measuring awareness; and the implicit-explicit interface. In this phase of interface research, the discussion was reframed and operationalization became a central concern addressed in a variety of experiments (e.g., Andringa \& Curcic, 2015; Bowles, 2011; Cintrón-Valentín \& Ellis, 2015; Kim \& Nam, 2017; Paciorek \& 
Williams, 2015). Perhaps a precursor to this second special issue was the comprehensive book by Ellis et al. (2009). The first two chapters of this volume are written by Ellis, defining and then operationalizing the constructs of explicit and implicit learning, testing, and teaching. Key criteria proposed for operationalizing the constructs of explicit and implicit learning and knowledge were as follows: degree of awareness, time available, focus of attention, systematicity, certainty, metalanguage, and learnability. However, as can be seen by a brief perusal of these criteria, the discussion has primarily been concerned with the acquisition of grammar. Although degree of awareness, time available, focus of attention, and perhaps learnability can all be applied to the learning and knowledge of vocabulary, clearly systematicity, certainty, and metalanguage have more to do with grammar learning. A review of almost 30 years of interface revealed that interface research has mostly been about grammar acquisition.

There is a clear justification for considering the interface with a focus on lexical learning. Pinker $(1998,2000)$ explains that "the vast expressive power of language is made possible by two principles: the arbitrary sound-meaning pairing underlying words, and the discrete combinatorial system underlying grammar" (p. 219). If one accepts that the combinatorial system of grammar and the soundmeaning pairings of words are two discrete components of language, then it would make sense to argue for distinguishing the interface for vocabulary acquisition as separate from the grammar acquisition interface. Some may argue that words and rules are such intertwined language components, that proposing separate interfaces for grammar and vocabulary learning is problematic. Nevertheless, it makes sense to say that operationalizing implicit vocabulary knowledge gains is more straightforward than operationalization is for grammar. This is because words are more simple and cohesive units to investigate than grammar rules, which can be riddled with complexity, exceptions, and irregularities. In the next section, interface research with a lexical bias will be discussed.

\section{Recently Completed Research Regarding the Vocabulary Interface}

In pivotal breakthrough research, Elgort $(2007,2011)$ investigated the effects of deliberate learning on individual words, combining traditional explicit measures such as a meaning generation test with online response time measures to gauge nondeclarative ${ }^{3}$ knowledge gains. She found that deliberate flashcard learning resulted in effects that could be regarded as an evidence of the acquisition of implicit knowledge. In a study on incidental learning during reading, Elgort and Warren (2014) explored the effects of contextual learning. Again, traditional declarative knowledge measures and nondeclarative tacit measures were used in the experimental design. Results revealed that in contextual L2 learning the number of encounters with words is the key predictor, but this learning is very complex and influenced by learner factors such as age, L2 lexical proficiency, first language, gender, learning strategies, and intrinsic versus extrinsic motivation. Further research on contextual learning investigated different aspects of word learning by monitoring participants' eye movements in real-time while reading (Elgort, Brysbaert, Stevens, \& Van Assche, 2018). Participants in this research 
were advanced English learners with vocabulary size averages estimated at 8,855 word families. The eye-tracking procedures focused on the contextual learning of low-frequency English words such as mulct that the experimenters tested by inserting them to replace mid-frequency counterparts (for this example, the word fine was replaced. Both mulct and fine mean "monetary penalty," or "compulsory payment"). Results from their investigation confirmed previous research findings that contextual word learning is a slow and incremental process. Furthermore, they explain that when cognitive processing resources are spent on understanding word meanings, reading conceptually sophisticated texts becomes far more problematic. They conclude the article explaining that their findings confirm that L2 reading materials should be carefully planned to meet the appropriate frequency levels required to provide conditions that make incidental learning possible. For teachers in Japan who teach learners with vocabulary sizes far less than half that of the participants found in Elgort et al. (2018), careful planning is necessary to assure that conditions favorable for incidental learning are present within course and curricular frameworks. Furthermore, a strong emphasis on deliberate learning activities is well justified.

So far in this article, the interface has been discussed with regard to grammar learning and individual word learning. However, the focus of the research conducted by the author aimed to expand from that in a different direction by investigating the declarative and nondeclarative knowledge development with regard to multiword figurative expressions. These are one of the types of expressions that Siyanova-Chanturia and Martinez (2015) refer to in their review of research in this area, which they umbrella under the term multi-word expressions (MWEs). To encompass all the different types, they defined MWEs loosely as fixed or semifixed, recurrent phrases, such as collocations (strong tea), binomials (black and white), multi-word verbs ( put up with), idioms (spill the beans), proverbs (better late than never), speech formulae (What's up?), and lexical bundles (in the middle of). Within these different types of MWEs, the objects of study would be called idioms.

However, the important distinction between literal expressions, figurative expressions, and core idioms must be mentioned. Figurative expressions such as dog eat dog (meaning "highly competitive"), once in a blue moon (meaning "rarely"), and walking on air (meaning "happy") can be interpreted, so once a person learns their meaning, the metaphorical connection can be made. Originally Grant and Bauer (2004) and subsequently Nation and Webb (2011) explained that figurative expressions are different from core idioms, for which the metaphorical meaning cannot be readily discerned. Examples of core idioms are kick the bucket (meaning "die"), red herring (meaning "distraction"), and spill the beans (meaning "expose a secret"). In idioms such as these, there is a higher learning burden for L2 learners than the learning burden for figurative and literal expressions.

In a recent research by the author, figurative expressions were the object of learning in the experimental treatment, and comparisons were made between deliberate paired-associate learning and incidental contextual learning on 73 participants. Figurative expressions that were learned through deliberate flashcard learning resulted in significantly faster online processing of semantic probes than did those that were learned contextually in the self-paced reading task. This was evidence that deliberate practice resulted in higher quality nondeclarative 
knowledge gains, an important finding that builds on understanding of individual word knowledge development gained from Elgort (2007, 2011). Also, deliberate learning resulted in significantly superior results on the meaning generation test of declarative knowledge, which makes sense and confirms abundant previous interface research in the relationship between deliberate learning and declarative knowledge. Finally, compared to controls, contextual learning also resulted in slightly faster processing of the semantic probes. This was evidence that contextual figurative expression learning also results in tacit knowledge development, but the developmental process may be slower and more uncertain. In the long run, however, phrases that are learned contextually may become more stable fluent knowledge, as this is the way they are naturally learned in the L1.

To summarize this discussion of the interface and the experiment conducted by the author, four main conclusions can be drawn:

1. Acquisition of nondeclarative tacit knowledge is a by-product of repetition and retrieval, regardless of whether that repetition and retrieval is incidental or deliberate. Tacit knowledge develops below the surface, underlying declarative knowledge. With regard to the learning of figurative expressions, there is some interfacing between the two learning and knowledge types.

2. Tacit learning is more likely to result in tacit, nondeclarative knowledge development and deliberate learning is more likely to result in declarative knowledge.

3. The simpler and more regular the L2 feature, the more quickly its tacit knowledge elements will develop. Thus, tacit individual word knowledge development is typically faster than tacit knowledge development for grammar.

4. Deliberate and contextual learning and declarative and nondeclarative knowledge development go hand in hand. All are essential for SLA development, and more effective when done together with their interface counterpart.

\section{Future Experiment Proposal}

This section explains a study proposed to be conducted in the spring of 2020, within two sections of an identical required English class for second year Japanese university EFL students who are non-English majors $(n=80)$. The class title is "Intensive Reading," which means that a large proportion of class activities should be focused on different types of deliberate learning in connection to text that are slightly above the learners' ability level. There is no need to balance between deliberate and incidental learning activities within this class because students also attend another class called "Extensive Reading" that is focused on incidental learning activities and promoting fluency development through easy reading. However, within this framework, different types of deliberate learning are conducted to balance along a scale between granular rote memory and broader, more contextual types of deliberate learning. The class is taught by the author. 


\subsection{Research Question Options}

With the above conclusions in mind, many further questions come to mind that should be addressed in future research following this agenda. In a future experiment, one of the following research questions will be investigated:

- What kind of paired-associate lexical learning is most effective?

o English target word / Japanese meaning (paired associates)

o English target word / English meaning (paired associates)

o English target word / CLOZE use sentence example + meaning (paired associates)

- Are there other learning pairs that will extend the capacity of Quizlet to accommodate for more contextual types of deliberate learning?

o Sentence stems / Sentence completions containing target word (paired associates)

o Sequential sentence stems / Sequential sentence completions (paired associates)

o Text comprehension questions / answers (paired associates)

- What kind of learning target is most effective?

o English target word

o English target word embedded in a short phrase to show grammatical collocations

- Actual tasks conducted throughout the class: For longer texts, are two-sided paper-based contextual paired-associate cards effective?

o Ten sentence sequence completion tasks (see Appendix A)

o 200-word CLOZE memorization task (see Appendix B)

\subsection{Materials}

The experimental conditions will be presented within the Quizlet sets themselves. Counterbalancing of learning conditions will be managed with Google Classroom. That is, at the beginning of the semester, students will be assigned to experimental treatment groups, and counterbalanced Quizlet sets will be assigned to each group accordingly within Google Classroom. Therefore, students will not be aware of the different learning groups that they are assigned into and will be doing nearly identical learning tasks side by side in the same classroom.

\subsection{Experimental Design Issues}

The experiment can be conducted over 6 to 13 weekly 20 -minute sessions. Time on task will be managed within the framework as all experimental conditions and testing instruments will be conducted during the class time under the auspices of a graded strand of the class called "Learning Strategy Training." To control for word learning burden and prior learning, pseudowords can be used. 


\subsection{Instrumentation}

There will be a balance of declarative, online-declarative, and online nondeclarative knowledge measures. Declarative knowledge tests could be a paper-based meaning generation test or online multiple-choice test. Frequent online multiple-choice tests will be administered using Google Classroom and scored using Flubaroo. Online declarative knowledge measures will be administered using E-Prime to test receptive retrieval, most likely in a multiple-choice format measuring response times and accuracy. Online nondeclarative knowledge will be measured using E-Prime in a lexical decision task format.

\section{Conclusion}

In this article, the acute need for Japanese students of English to learn many more words than they currently do was addressed. Furthermore, the need for learners, teachers, materials developers, and curriculum designers to balance between intentional and incidental learning opportunities was stressed. The review of interface research supported this necessity for balancing these two complementary learning types. This broad overview of over 30 years of interface research in second language acquisition research was explained in three main stages. The initial stage attempted to establish how implicit and explicit knowledge types interface. This was followed by a stage aimed at operationalizing interface constructs. The third and current stage of interface research focuses on awareness, methodological concerns, and measurement. Next, it was argued that the interface should be considered differently with regard to lexical learning versus grammar learning. Following this assertion, recent lexical (as opposed to grammatical) interface research was presented. Finally, the article concluded with a proposal for a future lexical interface experiment.

\section{Note}

1. In Schmitt's (2008) review, he refers to this as depth of knowledge, following a long tradition within the field. However, throughout this article the term knowledge quality will be used instead. This is done mainly because the concept of quality more accurately describes the useful, durable, fluent knowledge representations that should be developed. Furthermore, the construct of knowledge quality is more closely connected to speed and efficient retrieval than the traditional construct of depth, which is more about the complexity and elaborateness of the representations.

2. However, before getting too enthusiastic about this method, it must be noted that the knowledge gains it brings are greatly weakened if done in isolation. Although this article argues strongly in favor of the effectiveness of flashcard learning, this does not mean that it should result in neglecting incidental types of language learning. For maximum benefits, this activity must be balanced with other activities that provide abundant input and ample opportunities for incidental learning. Incidental and intentional learning are both equally essential, yet distinct parts of the language learning process. 
3. Elgort prefers the terms declarative and non-declarative or tacit over explicit and implicit because they more clearly define the nature of L2 knowledge here being discussed. The terms declarative and non-declarative more accurately specify the key distinction between knowledge about the L2 versus more intuitive, subconscious, tacit knowledge that is applied in fluent use. For the remainder of this article, these terms will be used exclusively.

\section{References}

Andringa, S., \& Curcic, M. (2015). How explicit knowledge affects online L2 processing. Studies in Second Language Acquisition, 37(2), 237-268. doi: $10.1017 / \mathrm{S} 0272263115000017$

Andringa, S., \& Rebuschat, P. (2015). New directions in the study of implicit and explicit learning. Studies in Second Language Acquisition, 37(2), 185-196. doi: $10.1017 / \mathrm{S} 027226311500008 \mathrm{X}$

Berwick, R., \& Ross, S. J. (1989). Motivation after matriculation: Are Japanese learners of English still alive after exam hell? JALT Journal, 11, 193-210.

Bowles, M. A. (2011). Measuring implicit and explicit linguistic knowledge. Studies in Second Language Acquisition, 33(2), 247-271. doi: 10.1017/ s0272263110000756

Cintrón-Valentín, M., \& Ellis, N. C. (2015). Exploring the interface. Studies in Second Language Acquisition, 37(2), 197-235. doi: 10.1017/S0272263115000029

DeKeyser, R. M. (1997). Beyond explicit rule learning. Studies in Second Language Acquisition, 19(2), 195-221. doi: 10.1017/S0272263197002040

DeKeyser, R. M. (1998). Beyond focus on form: Cognitive perspectives on learning and practicing second language grammar. In C. Doughty \& J. Williams (Eds.), Focus on form in classroom second language acquisition (pp. 42-63). Cambridge: Cambridge University Press.

Doughty, C., \& Williams, J. (1998). Pedagogical choices in focus on form. In C. Doughty \& J. Williams (Eds.), Focus on form in classroom second language acquisition (pp. 197-261). Cambridge, UK: Cambridge University Press.

Elgort, I. (2007). The role of intentional decontextualized learning in second language vocabulary acquisition: Evidence from primed lexical decision tasks with advanced bilinguals (Unpublished doctoral dissertation). Wellington, NZ: Victoria University of Wellington.

Elgort, I. (2011). Deliberate learning and vocabulary acquisition in a second language. Language Learning, 61(2), 367-413. doi: 10.1111/lang.2011.61.issue-2

Elgort, I., Brysbaert, M., Stevens, M., \& Van Assche, E. (2018). Contextual word learning during reading in a second language. Studies in Second Language Acquisition, 40(2), 341-366. doi: 10.1017/s0272263117000109

Elgort, I., \& Warren, P. (2014). L2 vocabulary learning from reading: Explicit and tacit lexical knowledge and the role of learner and item variables. Language Learning, 64(2), 365-414. doi: 10.1111/lang.2014.64.issue-2 
Ellis, N. (2005a). At the interface: Dynamic interactions of explicit and implicit language knowledge. Studies in Second Language Acquisition, 27(2), 305-352. doi: 10.1017/S027226310505014X

Ellis, R. (2005b). Measuring implicit and explicit knowledge of a second language: A psychometric study. Studies in Second Language Acquisition, 27(2), 141-172. Retrieved from http://journals.cambridge.org/abstract_S0272263105050096

Ellis, R., Loewan, S., Elder, C., Erlam, R., Philp, J., \& Reinders, J. (2009). Implicit and explicit knowledge in second language learning, testing, and teaching. Bristol, UK: Multilingual Matters.

Gorsuch, G. (1995). Tests, testing companies, educators, and students. The Language Teacher, 19(10), 37-40.

Grant, L., \& Bauer, L. (2004). Criteria for re-defining idioms: Are we barking up the wrong tree? Applied Linguistics, 25(1), 38-61. doi: 10.1093/applin/25.1.38

Hulstijn, J. (2003). Incidental and intentional learning. In K. Doughty \& M. Long (Eds.), The handbook of second language acquisition (pp. 349-382). Oxford: Wiley-Blackwell.

Hulstijn, J. (2005). Theoretical and empirical issues in the study of implicit and explicit second-language learning [Special Issue]. Studies in Second Language Acquisition, 27(2). doi: 10.1017/S0272263105050084

Hunt, A., \& Beglar, D. (2005). A framework for developing EFL reading vocabulary. Reading in a Foreign Language, 17(1), 23-59.

Kim, J., \& Nam, H. (2017). Measures of implicit knowledge revisited. Studies in Second Language Acquisition, 39(3), 431-457. doi: 10.1017/s0272263115000510

Krashen, S. D. (1982). Principles and practice in second language acquisition. Los Angeles, CA: Pergamon. Retrieved from http://www.sdkrashen.com/Principles_and_Practice/Principles_and_Practice.pdf

McLean, S., Hogg, N., \& Kramer, B. (2014). Estimations of Japanese university learners' English vocabulary sizes using the vocabulary size test. Vocabulary Learning and Instruction, 3(2), 47-55.

Miyazaki, I. (1981). China's examination hell: The civil service examinations of imperial China. New Haven, CT: Yale University Press.

Nakata, T. (2011). Computer-assisted second language vocabulary learning in a paired-associate paradigm: A critical investigation of flashcard software. Computer Assisted Language Learning, 24(1), 17-38. doi: 10.1080/09588221.2010.520675

Nation, P. (2007). The four strands. Innovation in Language Learning \& Teaching, 1(1), 2-13. doi: 10.2167/illt039.0

Nation, P. (2013). Learning vocabulary in another language (2nd edn.). New York, NY: Cambridge University Press.

Nation, P., \& Beglar, D. (2007). A vocabulary size test. The Language Teacher, 31(7), 9-13. Retrieved from jalt-publications.org/files/pdf/the_language_ teacher/07_2007tlt.pdff 
Nation, P., \& Yamamoto, A. (2012). Applying the four strands to language learning. International Journal of Innovation in English Language Teaching and Research, 1(2), 173. Retrieved from https://www.victoria.ac.nz/_data/ assets/pdf_file/0003/1626123/2012-Yamamoto-Four-strands.pdf

Nation, P., \& Webb, S. (2011). Researching and analyzing vocabulary. Boston, MA: Heinle Cengage Learning.

Norris, J. M., \& Ortega, L. (2000). Effectiveness of L2 instruction: A research synthesis and quantitative meta-analysis. Language Learning, 50(3), 417-528. doi: 10.1111/0023-8333.00136

Paciorek, A., \& Williams, J. N. (2015). Implicit learning of semantic preferences of verbs. Studies in Second Language Acquisition, 37(2), 359-382. doi: 10.1017/ S0272263115000108

Pinker, S. (1998). Words and rules. Lingua, 106(1-4), 219-242. doi: 10.1016/ S0024-3841(98)00035-7

Pinker, S. (2000). Words and rules: The ingredients of language. New York, NY: Harper Perennial.

Schmitt, N. (2008). Review article: Instructed second language vocabulary learning. Language Teaching Research, 12(3), 329. doi: 10.1177/1362168808089921

Siyanova-Chanturia, A., \& Martinez, R. (2015). The idiom principle revisited. Applied Linguistics, 36(5), 549-569. doi: 10.1093/applin/amt054 
Appendix A

Story Retelling Sentence Completion Activity (Prompts Side of Paper)

\section{Chapter 3 Retelling}

1. Chapter 3 is ...

2. Mr. Mimura regards time management ...

3. Mr. Mimura is irritated by

4. Mr. Mimura doesn't think Mr. Yagami should ...

5. Mr. Yagami explained that he was happy to ...

6. Mr. Uehara says that Mr. Mimura ...

7. Mr. Mimura realized that he should ...

8. The key is not to ... 


\section{Appendix A (continued)}

Story Retelling Sentence Completion Activity (Correct Responses Side of Paper)

\section{Chapter 3 Retelling}

1. Chapter 3 is about putting first things first.

2. Mr. Mimura regards time management as the most important thing at work.

3. Mr. Mimura is irritated by meetings that are longer than planned.

4. Mr. Mimura doesn't think Mr. Yagami should wait for customers who are late for their reservation.

5. Mr. Yagami explained that he was happy to wait because they are special for his restaurant.

6. Mr. Uehara says that Mr. Mimura should see life more broadly.

7. Mr. Mimura realized that he should take more time to discuss things with his boss.

8. The key is not to manage time but to manage ourselves. 


\section{Appendix B}

\section{Intensive Reading CLOZE Memorization Task (Prompts Side of Paper)}

\section{Habit 2: \\ Begin with the End in Mind}

(1) Everything made by people is created First, things are imagined, which means they are created in the is going to build a house, first they imagine a good design and draw a clear $\ldots . . . . . . .1$ that shows their plan. Second, the plan is used to the mind, and the actual need a clear:....... and plan of the life you want to make. With such a plan in mind, you can know exactly what needs to be

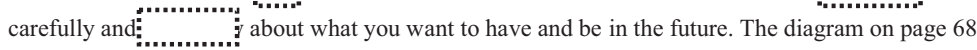
in the textbook shows the importance of having clear it's always very simple to know what you should do every moment of every day.

(2) A very effective way to statement focusses on what you want to (character), what you want to (contributions and achievements), and what reflect on, and revise regularly. Mission statements are unique, and reflect each person's individual statements. They reflect who you are, what you value, and what you want to

(3) For teachers, having a clear mission is their professional life Likewise, for class every day, and also for the whole school a teacher can easily interacting with students, they the $\cdots$ i...

(4) There's a song about this strong, feeling called I Can See Clearly Now. It's about the feeling of moving toward clear goals. Life has many that we must do see our goals overcome them. Having such a clear of rain, doubt, fear, and

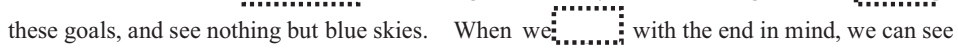
clearly both what we need to do now and what we wa............... to become. 


\section{Appendix B (continued)}

Intensive Reading CLOZE Memorization Task (Correct Responses Side of Paper)

\section{Habit 2: \\ Begin with the End in Mind}

(1) Everything made by people is created twice. First, things are imagined, which means they are created in the mind. Second, things are created in real life. For example, when an architect is going to build a house, first they imagine a good design and draw a clear image that shows their plan. Second, the plan is used to build the house. In this way, the image or plan is created first in the mind, and the actual house is created second. Building your life is like building a house. You need a clear image and plan of the life you want to make. With such a plan in mind, you can know exactly what needs to be done at any time. Beginning with the end in mind means thinking carefully and creatively about what you want to have and be in the future. The diagram on page 68 in the textbook shows the importance of having clear goals. When you have a clear goal in mind, it's always very simple to decide what is best to do. Having this clear image makes it much easier to know what you should do every moment of every day.

(2) A very effective way to clarify your life goals is to write a mission statement. A mission statement focusses on what you want to be (character), what you want to do (contributions and achievements), and what values you want to have. It's a clear written statement that you read often, reflect on, and revise regularly. Mission statements are unique, and different for everyone, but they reflect each person's individual changeless core. On page 70, there's an explanation of mission statements. They reflect who you are, what you value, and what you want to become.

(3) For teachers, having a clear mission is essential. When teachers have a clear mission, their professional life reflects their clear purpose, and students are inspired by their presence. Likewise, beginning with the end in mind is also essential for teachers. They should have a clear plan for class every day, and also for the whole school year. With a clear plan and a clear mission, a teacher can easily decide what to do in the various situations that arise every day. When interacting with students, they praise good behavior, scold bad behavior, and give grades according the goals they want their students to achieve.

(4) There's a song about this strong, purposeful feeling called I Can See Clearly Now. It's about the feeling of moving toward clear goals. Life has many obstacles, which are difficult things that we must do something about. But as the song says, when we see our goals clearly, we can overcome them. Having such a clear vision is like seeing a rainbow after a storm. The dark clouds of rain, doubt, fear, and uncertainty are no longer in our way. We look straight ahead, focused on these goals, and see nothing but blue skies. When we begin with the end in mind, we can see clearly both what we need to do now and what we want our life to become. 


\title{
Vocabulary Learning and Instruction
}

\author{
Volume 9, Number 2,
}

August 2020

doi: http://dx.doi.org/10.7820/vli.v09.2.2187-2759 


\section{VLI Editorial Team}

Editorial Board: Jeffrey Stewart, Raymond Stubbe, Aaron Gibson.

Reviewers: Paul Meara, Norbert Schmitt, John A. Read, Stuart Webb, John P. Racine, Tomoko Ishii, Tim Stoeckel, Dale Brown, Jon Clenton, Stuart McLean, Peter Thwaites, Tatsuya Nakata, Kiwamu Kasahara, Masumi Kojima, James Rogers, Yuko Hoshino, Vivienne Rogers, Yu Kanazawa, Phil Bennett, Tim Stoeckel, Ian Mumby, Pete Westbrook, Stephen Cutler.

Proof Readers: Alex Cameron, Andrew Gallacher, Peter Harold, Mark Howarth, Linda Joyce, Tim Pritchard, Andrew Thompson, Alonzo Williams, Melanie González, James Rogers, Charles Mueller, Jenifer Larson-Hall, Noriko Matsuda, David Beglar, Laurence Anthony, Paul Lyddon, Rick Romanko, Tatsuya Nakata, Ogawa Chie, Michael Holsworth, Darrell Wilkinson, Haidee Thomson, Clint Denison, Louis Lafleur, Andrew Obermeier, Irina Elgort.

The Editorial Team expresses a sincere thank you to Mana Ikawa, who designed the cover for the print version of $V L I$.

Copyright (C) 2020 Vocabulary Learning and Instruction, ISSN: Online 2187-2759; Print 2187-2767. All articles are copyrighted by their respective authors. 